\title{
Impact of alcohol disorder and the use of illicit drugs on tuberculosis treatment outcomes: a retrospective cohort study
}

\author{
Daniele M. Pelissari and Fredi A. Diaz-Quijano
}

\begin{abstract}
Background: Alcohol and illicit drugs are associated with the discontinuation of tuberculosis (TB) treatment and can compromise the immune system. We estimated the impact of alcohol disorder and the use of illicit drug on TB treatment outcomes, considering the interaction of both substances in patients from São Paulo state, Brazil.

Methods: This is a retrospective cohort of patients diagnosed with TB from 2011 to 2015. We estimated the relative risk (RR) of an unsuccessful outcome associated with alcohol disorder, use of illicit drugs and their interaction using a multiple regression model. We used the adjusted RR to estimate the population attributable fraction.

Results: Out of a total 77,212 TB patients, 22.2\% used at least one of the substances of interest during treatment, while $17 \%$ presented an unsuccessful outcome of TB treatment. Compared with no exposure to any substance, alcohol disorder alone (adjusted RR: 1.48; 95\% Cl: 1.4-1.56), drug use alone (adjusted RR: 2.1; 95\% Cl: 1.98-2.21) and exposure to both substances (adjusted RR: 2.09; 95\% Cl: 1.97-2.21) were all associated with a higher risk of an unsuccessful outcome. The adjusted RR of an unsuccessful outcome for people exposed to both substances was 32. 7\% (95\% Cl: 26.8-38.2\%) and 15.8\% (95\% Cl: 11.5-20.1\%) lower than expected on the multiplicative and additive scales respectively. Among all TB patients, $15.8 \%$ (95\% Cl: 15-16.5\%) of unsuccessful outcomes was attributable to those exposures.

Conclusions: We identified a negative interaction between alcohol disorder and the use of illicit drugs on TB treatment outcomes. Despite this, interventions to reduce substance use in TB patients could have a meaningful contribution to preventing unsuccessful treatment outcomes.
\end{abstract}

Keywords: Tuberculosis, Illicit drugs use, Alcohol disorder, Outcome, Interaction

\section{Background}

In 2016, 10.4 million new tuberculosis (TB) patients and 1.67 million deaths from the disease were registered worldwide [1]. Brazil is a middle-income country in South America. It is included in the list of the highest TB and TB-HIV burden countries issued by the World Health Organization (WHO) [1]. In 2017, 69,569 new TB patients were registered in the country; only $73 \%$ of them were cured [2]. The high percentage of unsuccessful outcomes in Brazil perpetuates transmission of the disease at the community level. This finding compromises the country's likelihood of meeting the target of $90 \%$

\footnotetext{
* Correspondence: danipelica@usp.br

Department of Epidemiology, School of Public Health, University of São Paulo, Av. Dr. Arnaldo, 715, São Paulo 01246-904, Brazil
}

reduction in $\mathrm{TB}$ incidence and $95 \%$ reduction in $\mathrm{TB}$ deaths by 2035 , as set by the WHO's End TB Strategy [3].

Alcohol consumption is related to pharmacokinetic alterations of the medicines used in TB treatment [4], and the use of both alcohol and illicit drugs is associated with discontinuing treatment [5-7] and compromising the immune system [8]. Therefore, these substances have common mechanisms to affect TB treatment outcomes, possibly leading to either a saturation or an amplification of their effects.

None of the existing epidemiological studies that analysed the association of those substances with $\mathrm{TB}$ treatment outcomes have tested the interaction between both exposures $[5-7,9]$. However, understanding their relationship could be essential to properly estimating the

(c) The Author(s). 2018 Open Access This article is distributed under the terms of the Creative Commons Attribution 4.0 International License (http://creativecommons.org/licenses/by/4.0/), which permits unrestricted use, distribution, and 
population impact of these potentially modifiable risk factors on unsuccessful TB treatment outcome. Consequently, we estimated the impact of alcohol disorder and the use of illicit drugs on TB treatment outcomes considering the interaction of both substances, in patients from São Paulo state, Brazil.

\section{Methods}

This is a retrospective cohort of TB patients diagnosed from 2011 to 2015, based on surveillance data from the Tuberculosis Cases Notification and Monitoring System (TBWEB) updated in May 2017. This system only covers São Paulo state, representing approximately $25.5 \%$ of Brazilian new TB cases [2]. TBWEB records data collected by health professionals in a standardized TB notification form and allows follow-up on TB outcomes even if patients are transferred among health facilities. As a result, only a few cases in the study period did not have outcome data; when it did happen, it was mainly related to transfers out of São Paulo state.

\section{Study population}

We included new TB cases (never treated before or those that previously had received TB treatment for a period $\leq 1$ month), aged $\geq 15$ years, and who started TB treatment during the study period. We intended to focus the study on drug-sensitive TB cases; therefore, we excluded those patients recorded as having TB drug-resistant. From the possible study population of 79,075 patients, 1863 (2.4\%) patients did not have a TB outcome recorded. Therefore, in total, 77,212 patients were available for the outcome analysis.

As we included all patient information available during the study period, a sample size was not calculated in advance. Given the number of patients included, the frequency of exposures to substances (Table 1) and an incidence of the outcome in the unexposed group of $14.3 \%$, this study had a power higher than $99 \%$ to evaluate associations with a relative risk (RR) of 1.2 or greater for any of the exposure categories (alcohol, drugs or both).

\section{Variables}

Using WHO definitions as adapted to TBWEB, the main TB treatment outcomes were classified as treatment success (cured or completed treatment) or unsuccessful TB treatment outcome (death and lost to follow-up) [10].

Alcohol disorder, the use of illicit drugs and an interaction between them were analysed as the main independent variables. Alcohol disorder is collected in the TB notification form as the presence or not of an associated disorder and is categorized as yes or no. For the definition of alcohol disorder, Brazil adopts the American Psychiatric Association definition [11]. The use of illicit drugs is also collected in the notification form as a dichotomous variable (yes or no).

Substance exposures were identified by health professionals during clinical interviews. Thus, substance exposures were routinely recorded at the time of diagnosis, which is before the start of treatment.

\section{Statistical analysis}

We estimated the RRs and their 95\% confidence intervals $(95 \% \mathrm{CI})$ in a multiple model using Poisson regression with robust variance [12]. We obtained a model with the following structure:

$$
\operatorname{Ln}(y)=\beta_{0}+\beta_{a} X_{a}+\beta_{d} X_{d}+\beta_{a \wedge d} X_{a \wedge d}+\sum_{i=1}^{k} \beta_{i} C_{i}
$$

where $y$ represents the predicted value of the dependent variable; $\beta_{0}$ is the intercept; $\beta_{a}, \beta_{d}$ and $\beta_{a \wedge d}$ represent the regression coefficients of the dichotomous independent variables (adopting values of 0 [no] or 1 [yes]) that correspond to exposure to alcohol $\left(X_{a}\right)$, to illicit drugs $\left(X_{d}\right)$ and to the interaction term defining the concomitant exposures to both alcohol and drugs $\left(X_{a \wedge d}\right)$ respectively.

This model was adjusted by a number $(k)$ of covariates $\left(C_{i}\right)$ with their corresponding coefficients $\left(\beta_{i}\right)$. We considered the following covariates, which have been recognized as factors associated with TB outcome in previous studies $[5-7,9]$ : sex; age group (15 to $34 ; 35$ to 49,50 and older); race (blacks and non-blacks); HIV status; clinical form of TB (pulmonary [includes mixed form] and extrapulmonary); prisoner; homeless population; and directly observed treatment (DOT).

From this model, compared with the category of non-exposed to either alcohol or drug, the adjusted RRs for only alcohol $\left(R R_{a 0}\right)$, only drug $\left(R R_{0 d}\right)$ and for the exposure to both substances $\left(R R_{a d}\right)$ were calculated respectively as: $R R_{a 0}=\exp \left(\beta_{a}\right) ; R R_{0 d}=\exp \left(\beta_{d}\right)$; and $R R_{a d}=$ $\exp \left(\beta_{a}+\beta_{d}+\beta_{a \wedge d}\right)$.

We calculated the ratio of RRs as a measure of interaction on the multiplicative scale, consisting of the ratio of $R R_{a d}$ to the RR expected from the product of the effects of the two exposures considered separately [13]. Then,

$$
\text { ratio of } R R s=\frac{R R_{a d}}{R R_{a 0} R R_{0 d}}=\exp \left(\beta_{a \wedge d}\right)
$$

We also calculated the relative excess risk due to interaction (RERI) as a measure of additive interaction [13] as follows: $R E R I=R R_{a d}-\left(R R_{a 0}+R R_{0 d}-1\right)=R R_{a d}$ $-R R_{a 0}-R R_{0 d}+1$.

With a ratio of RRs $>1$ and RERI $>0$, we would consider an interaction as positive in the multiplicative and the additive scales, respectively. However, in the case of a ratio of $R R s<1$ and a $R E R I<0$, we interpreted the interaction as negative and calculated how much lower 
Table 1 Factors associated with unsuccessful tuberculosis treatment outcome, São Paulo-state, Brazil, 2011-2015

\begin{tabular}{|c|c|c|c|c|c|}
\hline \multirow[t]{2}{*}{ Characteristics } & \multirow[t]{2}{*}{ Total } & \multicolumn{2}{|c|}{ Incidence of unsuccessful outcome of tuberculosis treatment } & \multirow{2}{*}{$\begin{array}{l}\text { Crude RR } \\
(95 \% \mathrm{Cl})^{\mathrm{a}}\end{array}$} & \multirow{2}{*}{$\begin{array}{l}\text { Adjusted RR } \\
(95 \% \mathrm{Cl})^{\mathrm{a}}\end{array}$} \\
\hline & & No. & $\%$ & & \\
\hline Overall & 77,212 & 13,300 & 17 & & \\
\hline \multicolumn{6}{|l|}{ Alcohol and illicit drug } \\
\hline Neither & 60,107 & 8607 & 14.3 & 1 & 1 \\
\hline Only alcohol disorder & 7487 & 1765 & 23.6 & $1.65(1.57-1.72)$ & $1.48(1.4-1.56)$ \\
\hline Only drug use & 5199 & 1472 & 28.3 & $1.98(1.89-2.07)$ & $2.1(1.98-2.21)$ \\
\hline Alcohol disorder and drug use & 4418 & 1456 & 33 & $2.3(2.2-2.41)$ & $2.09(1.97-2.21)$ \\
\hline \multicolumn{6}{|l|}{ Sex } \\
\hline Female & 22,498 & 3102 & 13.8 & 1 & 1 \\
\hline Male & 54,714 & 10,198 & 18.6 & $1.35(1.3-1.4)$ & $1.27(1.22-1.32)$ \\
\hline \multicolumn{6}{|l|}{ Age (years) } \\
\hline $15-34$ & 36,080 & 5370 & 14.9 & 1 & 1 \\
\hline $34-49$ & 21,681 & 4068 & 18.8 & $1.26(1.21-1.31)$ & $0.99(0.94-1.03)$ \\
\hline 50 and more & 19,451 & 3862 & 19.9 & $1.33(1.28-1.38)$ & $1.23(1.18-1.29)$ \\
\hline \multicolumn{6}{|l|}{ Race } \\
\hline Non-black & 35,707 & 5727 & 16 & 1 & 1 \\
\hline Black & 33,135 & 5951 & 18 & $1.12(1.08-1.16)$ & $1.13(1.09-1.17)$ \\
\hline \multicolumn{6}{|l|}{ HIV } \\
\hline No & 69,973 & 10,582 & 15.1 & 1 & 1 \\
\hline Yes & 7239 & 2718 & 37.5 & $2.48(2.4-2.57)$ & $2.16(2.07-2.26)$ \\
\hline \multicolumn{6}{|l|}{ Clinical form } \\
\hline Pulmonary & 65,271 & 11,364 & 17.4 & 1 & 1 \\
\hline Extrapulmonary & 11,903 & 1899 & 16 & $0.92(0.88-0.96)$ & $0.86(0.82-0.9)$ \\
\hline \multicolumn{6}{|l|}{ Prison } \\
\hline No & 68,228 & 12,608 & 18.5 & 1 & 1 \\
\hline Yes & 8984 & 692 & 7.7 & $0.42(0.39-0.45)$ & $0.51(0.47-0.56)$ \\
\hline \multicolumn{6}{|l|}{ Homeless } \\
\hline No & 75,218 & 12,278 & 16.3 & 1 & 1 \\
\hline Yes & 1993 & 1022 & 51.3 & $3.14(3-3.29)$ & $2(1.89-2.13)$ \\
\hline \multicolumn{6}{|l|}{ Directly observed treatment } \\
\hline No & 16,791 & 4237 & 25.2 & 1 & 1 \\
\hline Yes & 54,940 & 7198 & 13.1 & $0.52(0.5-0.54)$ & $0.55(0.53-0.57)$ \\
\hline
\end{tabular}

$R R$ relative risk, $95 \% \mathrm{Cl}$ 95\% confidence interval

${ }^{a}$ Boldface indicates statistical significance $(p<0.05)$

the $R R_{a d}$ was than expected in both scales. Thus, we defined that proportion lower than expected in the multiplicative scale as: $1-\frac{R R_{a d}}{\left(R R_{a 0} R R_{0 d}\right)}$; and in the additive scale as: $1-\frac{R R_{a d}}{\left(R R_{a 0}+R R_{0 d}-1\right)}$.

Subsequently, we simulated the incidence expected from the adjusted RR using the incidence observed in the population not exposed to either alcohol disorder or use of illicit drugs as a reference. These incidences were then compared with those expected in additive and multiplicative scales, based on the sum of attributable risk and the product of RRs respectively. We followed the recommendations made by Knol and VanderWeele [14] to present interaction analyses.

Finally, we estimated the population attributable fraction (PAF) [15] of the use of substances for the risk of unsuccessful outcome of TB treatment using the formula:

$$
\mathrm{PAF}=p^{\prime} \frac{\theta-1}{\theta}
$$

where $\mathrm{p}^{\prime}$ is the prevalence of exposure to substances in the non-successful treatment population, and $\theta$ is the 
adjusted RR estimated by the regression model. PAF and interaction measures derived from the regression model were calculated using a nonlinear combination of parameter estimates based on the delta method [16].

To evaluate whether missing outcomes could affect the results, we first compared profile patients with and without treatment outcome registration using the Pearson Chi-square test (Additional file 1: Table S1). Because those populations were slightly different, we ran a sensitivity analysis with all unrecorded treatment outcomes set to either successful or unsuccessful (Additional file 2: Table S2).

All analyses were performed on Stata 12 (Stata Corporation, Texas USA).

\section{Results}

Of the total of $77,212 \mathrm{~TB}$ patients, $22.2 \%$ were exposed to at least one of the conditions (alcohol disorder or use of illicit drugs) at the beginning of TB treatment, and the overall incidence of unsuccessful outcome was $17 \%$. In the multiple model, exposure to only alcohol disorder (RR: 1.48 ; 95\% CI: 1.4-1.56), to only use of illicit drugs (RR: $2.1 ; 95 \%$ CI: $1.98-2.21$ ) and to both substances (RR: 2.09; 95\% CI: 1.97-2.21) were all associated with a higher risk of unsuccessful treatment outcome compared with patients not exposed to any of these conditions. The other risk factors significantly associated with a higher risk of the unsuccessful treatment outcome were: male sex, age over 50 years (compared with the group aged between 15 and 34 years), black race, coinfection with HIV and homeless population. Protective factors were extrapulmonary clinical form, prisoners and DOT (Table 1). All these associations were also observed in the models considered in the sensitivity analysis (Additional file 2: Table S2).

The adjusted RR for the group exposed to both alcohol disorder and illicit drug use (RR: 2.09; 95\% CI: 1.972.21 ) was $32.7 \%$ (95\% CI: $26.8-38.2 \%)$ lower than expected on the multiplicative scale and $15.8 \%$ (95\% CI: 11.5-20.1\%) lower than expected on the additive scale $(P<0.001$ for interaction on both scales) (Table 2). Consequently, the ratio of RRs was 0.67 (95\% CI: 0.62-0.73; $P<0.001)$ and the RERI was negative $(-0.49$; $95 \% \mathrm{CI}$ : $-0.65--0.33 ; P<0.001)$. Thus, we observed a negative interaction of alcohol disorder and drug use on the TB outcome that was statistically significant in both the multiplicative and additive scales.

According to the simulation, the expected incidences of unsuccessful outcome in the group exposed to both substances would be 36.3 and $43.7 \%$ in the additive and the multiplicative scales, respectively. However, the incidence predicted by the adjusted RR of the group exposed to both substances was $29.4 \%$ (Fig. 1).

From the multiple model, the estimated PAFs for an unsuccessful outcome of treatment were 4.3\% (95\% CI: 3.8-4.8\%), 5.8\% (95\% CI: 5.5-6.1\%) and 5.7\% (95\% CI: 5.4-6.0\%) for only alcohol disorder, only illicit drug use and both exposures, respectively. The joint PAF for these factors totalled 15.8\% (95\% CI: 15.0-16.5\%). According to the sensitivity analysis, this joint PAF would be $15.8 \%$ (95\% CI: $15.1-16.6 \%$ ) if all patients with a missing outcome were set to successful treatment and 13.8\% (95\% CI: $13.1-14.5 \%)$ if they were set to unsuccessful treatment (Table 3).

We represented the key messages of the association of alcohol disorder and illicit drug use on tuberculosis treatment outcome in an infographic in the Additional file 3: Figure S1.

\section{Discussion}

Our study showed a statistically significant interaction between alcohol disorder and illicit drug use on unsuccessful TB treatment outcomes. Specifically, the incidence of unsuccessful outcomes among patients exposed

Table 2 Interaction between alcohol disorder and illicit drug use on the risk of unsuccessful tuberculosis treatment outcome, São Paulo-state, Brazil, 2011-2015

\begin{tabular}{|c|c|c|c|c|c|}
\hline & \multicolumn{2}{|l|}{ Non-illicit drug use } & \multicolumn{2}{|l|}{ Illicit drug use } & \multirow{2}{*}{$\begin{array}{l}\text { RRs }(95 \% \mathrm{Cl})^{a} \\
\text { for illicit } \\
\text { drug within } \\
\text { strata of } \\
\text { alcohol }\end{array}$} \\
\hline & $\begin{array}{l}\text { No. of unsuccessful outcome/ } \\
\text { successful outcome }\end{array}$ & $\begin{array}{l}\text { RR } \\
(95 \% \mathrm{Cl})^{\mathrm{a}}\end{array}$ & $\begin{array}{l}\text { No. of unsuccessful outcome/ } \\
\text { successful outcome }\end{array}$ & $\begin{array}{l}\text { RR } \\
(95 \% \mathrm{Cl})^{\mathrm{a}}\end{array}$ & \\
\hline \multirow[t]{2}{*}{ Non-alcohol disorder } & $8607 / 51500$ & & $1472 / 3727$ & & \\
\hline & & 1 & & $\begin{array}{l}2.1(1.98-2.21) \\
P<0.001\end{array}$ & $\begin{array}{l}2.1(1.98-2.21) \\
P<0.001\end{array}$ \\
\hline \multirow[t]{2}{*}{ Alcohol disorder } & $1765 / 5722$ & & $1456 / 2962$ & & \\
\hline & & $\begin{array}{l}1.48(1.4-1.56) \\
P<0.001\end{array}$ & & $\begin{array}{l}2.09(1.97-2.21) \\
P<0.001\end{array}$ & $\begin{array}{l}1.41(1.31-1.51) \\
P<0.001\end{array}$ \\
\hline $\begin{array}{l}\text { RRs }(95 \% \mathrm{Cl})^{\mathrm{a}} \text { for alcohol within } \\
\text { strata of illicit drug }\end{array}$ & & $\begin{array}{l}1.48(1.4-1.56) \\
P<0.001\end{array}$ & & $\begin{array}{l}1.00(0.93-1.06) \\
P=0.90\end{array}$ & \\
\hline
\end{tabular}




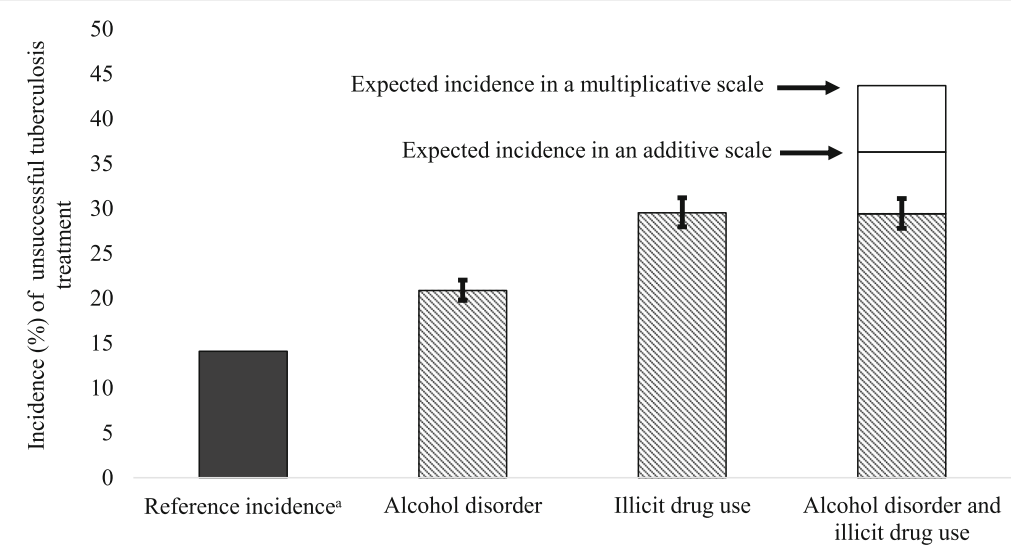

Fig. 1 Incidence of unsuccessful tuberculosis treatment outcome predicted by adjusted relative risk vs. that expected in multiplicative and additive scales according to alcohol disorder or illicit drug use, São Paulo-state, Brazil, 2011-2015. 'Reference incidence corresponds to the incidence observed in patients not exposed to either alcohol or illicit drugs (14.3\%). Other incidences presented correspond to the product of the reference incidence and the corresponding relative risk adjusted by sex, age, race, HIV, clinical form of TB, prison, homeless, and directly observed treatment

to both alcohol disorder and illicit drug use was lower than that expected from either the sum or the product of the estimated effects of the two exposures considered separately.

According to our results, association with only the use of illicit drugs was similar to that with both substances; therefore, alcohol disorder did not seem to contribute with an additional risk to illicit drug users. Illicit drug use can influence TB outcomes through its biological effects, social marginalization or by affecting adherence to treatment, which are mechanisms also associated with alcohol addiction $[5,7,8]$. However, we hypothesize that the use of illicit drugs (more than alcohol disorder) has the potential to influence and transform a patient's social network, creating obstacles to family support [17]. In addition, the illegal character of drug use, treatment barriers, including poor adherence and limited access to care, represent major challenges for treatment of drug users [18] than alcohol users.

In our study, we found that $14.5 \%$ of TB patients had alcohol disorder, and $12.7 \%$ used illicit drugs. The prevalence of alcohol disorder in the TB patients from this study was similar to that observed in the Brazilian capital's population aged 8 years and older in 2013 (16.4\%) [19]. Data about drug consumption are not routinely collected in Brazil. However, in 2005, a survey conducted with 200,000 Brazilians aged 12 or older estimated that the use of drugs (except alcohol and tobacco) in the past month was $4.5 \%$ [20], noticeably lower than that observed in the study's population of TB patients. Because the general population may be less likely to admit illegal drug use, information bias could be a possible explanation for these differences. Alternatively, the higher risk of TB among illegal drug users [18] could explain the higher prevalence of drug use in TB patients compared with the general population.

We also found that even with the negative interaction, almost $16 \%$ of unsuccessful treatment outcomes were attributable to substance exposures. Eliminating those substances from the population would be difficult, but reducing consumption to a much lower level is possible. One of the most effective strategies, tested by Milkman in teenagers in Iceland, is replacing the sensation created by substance use for one provided by the practice of

Table 3 Adjusted fraction of unsuccessful outcomes in a population of TB patients that was attributable to alcohol disorder and illicit drug use (PAF\%), São Paulo-state, Brazil, 2011-2015

\begin{tabular}{|c|c|c|c|}
\hline Alcohol and illicit drug & $\begin{array}{l}\text { Main analysis } \\
\text { PAF }(95 \% \mathrm{Cl})\end{array}$ & $\begin{array}{l}\text { Model 1 1,b } \\
\text { PAF (95\% Cl) }\end{array}$ & $\begin{array}{l}\text { Model 2a,b } \\
\text { PAF (95\% Cl) }\end{array}$ \\
\hline \multicolumn{4}{|l|}{ Neither } \\
\hline Only alcohol disorder & $4.3(3.8-4.8)$ & $4.3(3.8-4.8)$ & $3.7(3.3-4.2)$ \\
\hline Only drug use & $5.8(5.5-6.1)$ & $5.8(5.5-6.1)$ & $5(4.8-5.3)$ \\
\hline Alcohol disorder and drug use & $5.7(5.4-6.0)$ & $5.7(5.4-6)$ & $5(4.7-5.3)$ \\
\hline Total & $15.8(15.0-16.5)$ & $15.8(15.1-16.6)$ & $13.8(13.1-14.5)$ \\
\hline
\end{tabular}

PAF Population Attributable Fraction, 95\% Cl 95\% confidence interval

${ }^{a}$ Estimates based on relative risks adjusted by sex, age, race, HIV, clinical form of TB, prison, homeless and directly observed treatment

${ }^{\mathrm{b}}$ Model 1- unobserved treatment outcomes set to successful; model 2- unobserved treatment outcomes set to unsuccessful 
physical activities they wanted to do [21]. With this strategy, the rates of alcohol usage in the past month decreased from $42 \%$ in 1998 to $5 \%$ in 2016, and of cannabis from 17 to $5 \%$ [21]. Although challenging, government officials in Iceland turned that strategy into public policies, increasing public funding for youth sports and clubs, among other strategies [22].

\section{Limitations}

Underreporting of exposures and non-standardized data collection procedures could lead to an information bias. However, we believe that any underreporting or misclassification of the exposures would be no differential between the categories of the outcome and therefore would lead to an underestimation of the associations. Another limitation is that the routine surveillance system used as the data source in this retrospective cohort does not contain detailed information about levels of consumption. This limitation could lead to an incomplete adjustment and limit the analysis of the interaction mechanism. Local legislation defines the list of the illicit substances [23]. In a 2015 survey, the illicit drugs most used in Brazil were reported to be cannabis (50.8\%), lysergic acid diethylamide (LSD) (19.5\%), cocaine (12.8\%) and ecstasy (12.2\%) [24]. However, information about the type of substance of illicit drug is not systematically collected so was not possible to be analysed in this study.

Despite these limitations, the exposure categories we used in this study are widely used by the surveillance system. Moreover, because substance exposures are recorded before starting the TB treatment, our findings support that alcohol disorder and use of illicit drugs are predictors of an unsuccessful outcome. Therefore, this study suggests that routine collected information about substance exposures can be useful to identify TB patients at risk of unsuccessful outcomes and focus on preventive strategies.

\section{Conclusion}

We identified a negative interaction between alcohol disorder and illicit drug use on TB treatment outcomes. Despite this negative interaction, a substantial proportion of unsuccessful treatment outcomes would be potentially preventable if both alcohol and drug exposures were eliminated from this population. This suggests that integrated public policies to prevent or reduce substance use in TB patients could have a meaningful impact on treatment outcomes and should be prioritized.

\section{Additional files}

Additional file 1: Table S1. Profile study population with and without tuberculosis treatment outcome registration, São Paulo-state, Brazil, 2011-2015 $(n=79,075)$. (DOCX $23 \mathrm{~kb})$
Additional file 2: Table S2. Factors associated with unsuccessful tuberculosis treatment outcome with all unobserved treatment outcomes set to either successful (model 1) or unsuccessful (model 2), São Paulo-state, Brazil, $2011-2015$ ( $n=79,075)$. (DOCX $20 \mathrm{~kb})$

Additional file 3: Figure S1. Key messages of the association of alcohol disorder and illicit drug use on tuberculosis treatment outcome. São Paulo-state, Brazil, 2011-2015. (DOCX 329 kb)

\section{Abbreviations}

Cl: Confidence interval; DOT: Directly observed treatment; PAF: Population attributable fraction; RR: Relative risk; TB: Tuberculosis; TBWEB: Tuberculosis Cases Notification and Monitoring System

\section{Availability of data and materials}

Datasets of tuberculosis cases in Brazil are available by request at the Ministry of Health:

- Click the link: https://esic.cgu.gov.br/sistema/site/index.aspx

- Select the form to make a new registration

- Register your request for access to data, including details on the

information and indicators you have an interest in, and send the request

\section{Authors' contributions}

DMP and FADQ gave substantial contributions to conception and design. DMP acquired the data and wrote the first draft. FADQ reviewed it critically for content. Both authors conducted the analyses, interpreted the data and approved the final version.

\section{Ethics approval and consent to participate}

Data used in this study do not include personal identification of TB patients. Additionally, all data analysed are publicly available in Brazil. According to local legislation (Resolution No. 510 of the National Health Council of Brazil), research conducted exclusively with publicly data is not evaluated by an institutional review board. However, this study was conducted according to guidelines and standards for research involving human subjects.

Consent for publication

Not applicable. This study used retrospective surveillance routine database.

\section{Competing interests}

The authors declare that they have no competing interests.

\section{Publisher's Note}

Springer Nature remains neutral with regard to jurisdictional claims in published maps and institutional affiliations.

Received: 12 February 2018 Accepted: 15 June 2018

Published online: 12 July 2018

References

1. World Health Organization. Global tuberculosis report 2017. Geneva: WHO; 2017.

2. Ministério da Saúde. Implementation of the end TB National Plan as a public health problem in Brazil: first steps towards achieving the goals. Bol Epidemiológico. 2018;49:1-18.

3. Uplekar M, Weil D, Lonnroth $\mathrm{K}$, Jaramillo E, Lienhardt C, Dias HM, et al. WHO's new end TB strategy. Lancet. 2015; https://doi.org/10.1016/S01406736(15)60570-0.

4. Rehm J, Samokhvalov AV, Neuman MG, Room R, Parry C, Lönnroth K, et al. The association between alcohol use, alcohol use disorders and tuberculosis (TB). A systematic review. BMC Public Health. 2009;9:450. https://doi.org/10. 1186/1471-2458-9-450.

5. Ranzani OT, Carvalho CRR, Waldman EA, Rodrigues LC. The impact of being homeless on the unsuccessful outcome of treatment of pulmonary TB in São Paulo State, Brazil. BMC Med. 2016;14 https://doi.org/10.1186/s12916016-0584-8

6. Harling G, Lima Neto AS, Sousa GS, Machado MMT, Castro MC. Determinants of tuberculosis transmission and treatment abandonment in Fortaleza, Brazil. BMC Public Health. 2017;17:508. https://doi.org/10.1186/ s12889-017-4435-0. 
7. Costa-Veiga A, Briz T, Nunes C. Unsuccessful treatment in pulmonary tuberculosis: factors and a consequent predictive model. Eur J Pub Health. 2017; https://doi.org/10.1093/eurpub/ckx136.

8. Donahoe RM, Adler MW. Substance abuse and the immune system. Drug Alcohol Depend. 2001;62:109-10.

9. García-Basteiro AL, Respeito D, Augusto OJ, López-Varela E, Sacoor C, Sequera VG, et al. Poor tuberculosis treatment outcomes in southern Mozambique (2011-2012). BMC Infect Dis. 2016;16 https://doi.org/10.1186/ s12879-016-1534-y.

10. Definitions and reporting framework for tuberculosis -2013 revision. Geneva: WHO Publications; 2013.

11. American Psychiatric Association. Diagnostic and Statistical Manual of Mental Disorders, Fifth Edition. Arlington: American Psychiatric Association; 2013.

12. Barros AJD, Hirakata VN. Alternatives for logistic regression in cross-sectional studies: an empirical comparison of models that directly estimate the prevalence ratio. BMC Med Res Methodol. 2003;3:21. https://doi.org/10.1186/ 1471-2288-3-21.

13. VanderWeele TJ, Knol MJ. A tutorial on interaction. Epidemiol Methods. 2014:3:33-72.

14. Knol MJ, VanderWeele TJ. Recommendations for presenting analyses of effect modification and interaction. Int J Epidemiol. 2012;41:514-20. https:// doi.org/10.1093/ije/dyr218

15. Mansournia MA. Population attributable fraction. BMJ. 2018;360 https://doi. org/10.1136/bmj.k757.

16. Hosmer D, Lemeshow S. Confidence interval estimation of interaction. Epidemiol Camb Mass. 1992:3:452-6.

17. Barbosa de Pinho L, Ramos Oliveira I, Cardozo Gonzales RI, Harter J. Consumo de crack: repercusiones en la estructura y en la dinámica de las relaciones familiares. Enferm Glob. 2012;11:139-49. https://doi.org/10.4321/ S1695-61412012000100009

18. Deiss RG, Rodwell TC, Garfein RS. Tuberculosis and illicit drug use: review and update. Clin Infect Dis. 2009;48:72-82. https://doi.org/10.1086/594126.

19. Munhoz TN, Santos IS, Nunes BP, de Mola CL, da Silva ICM, Matijasevich A. Tendências de consumo abusivo de álcool nas capitais brasileiras entre os anos de 2006 a 2013: análise das informações do VIGITEL. Cad Saúde Pública. 2017;33(7):e00104516.

20. Carlini EA, Galduróz JCF, Noto AR, Nappo SA. II Levantamento domiciliar sobre o uso de drogas psicotrópicas no Brasil: estudo envolvendo as 108 maiores cidades do país. São Paulo UNIFESP. 2002;

21. Milkman HB. Iceland Succeeds at Reversing Teenage Substance Abuse The US Should Follow Suit. https://www.drugfree.org.au/images/pdf-files/ibrary/ iceland/Iceland_Succeeds_at_Reversing_Teenage_Substance_Abuse.pdf. (Accessed 13 May 2018.

22. Enos G. Iceland's activity-heavy prevention approach scarce in United States. Alcohol Drug Abuse Wkly. 2017;29:1-8.

23. Ministério da Saúde, Agência Nacional de Vigilância Sanitária. Portaria no 344, de 12 de maio de 1998. Aprova o regulamento técnico sobre substâncias e medicamentos sujeitos a controle especial. Brasília: Diário Oficial da União; 1998. http://anvisa.gov.br/legis/portarias/344_98.htm.

24. Global Drug Survey. The Global Drug Survey 2015 findings. https:// www.globaldrugsurvey.com/the-global-drug-survey-2015-findings/ (Accessed 23 April 2018).

\section{Ready to submit your research? Choose BMC and benefit from:}

- fast, convenient online submission

- thorough peer review by experienced researchers in your field

- rapid publication on acceptance

- support for research data, including large and complex data types

- gold Open Access which fosters wider collaboration and increased citations

- maximum visibility for your research: over $100 \mathrm{M}$ website views per year

At BMC, research is always in progress.

Learn more biomedcentral.com/submissions 